\title{
ENSINO POR INVESTIGAÇÃO EM AULAS DE CIÊNCIAS: RECONSTRUÇÃO DE IDEIAS DOS ALUNOS SOBRE FLUXO DE ENERGIA
}

\section{TEACHING BY INVESTIGATION IN SCIENCE CLASSES: REBUILDING STUDENT'S IDEAS ABOUT ENERGY FLOW.}

\author{
Fabiana Brandelero Cezar ${ }^{1}$, Aline Alves da Silva ${ }^{2}$, Daniela Frigo Ferraz ${ }^{3}$, Lourdes \\ Aparecida Della Justina ${ }^{4}$ \\ ${ }^{1}$ Universidade Estadual do Oeste do Paraná/Unioeste - (Campus Cascavel) / Curso de Ciências \\ Biológicas, E-mail: fabianabrandelero@yahoo.com.br \\ ${ }^{2}$ Universidade Estadual do Oeste do Paraná/Unioeste - (Campus Cascavel) / Programa de Pós-Graduação \\ em Educação, E-mail: Nyne_alves@hotmail.com \\ ${ }^{3}$ Universidade Tecnológica Federal do Paraná/UTFPR - (Campus Ponta Grossa), Programa de Pós- \\ Graduação em Ensino de Ciência e Tecnologia. E-mail:dfrigoferraz@ gmail.com \\ ${ }^{4}$ Universidade Estadual do Oeste do Paraná/Unioeste - (Campus Cascavel) / Centro de Ciências \\ Biológicas e da Saúde, E-mail: lourdesjustina@gmail.com
}

\begin{abstract}
RESUMO
O conhecimento ecológico atual aponta que todos os seres vivos, direta ou indiretamente, dependem da energia solar para a sobrevivência e que as relações alimentares entre os seres vivos não são lineares. O objetivo do presente trabalho foi diagnosticar as percepções dos alunos sobre $\mathrm{o}$ fluxo de energia durante $\mathrm{o}$ desenvolvimento de um módulo didático com abordagem investigativa no contexto de um subprojeto do PIBID. Para tanto se desenvolveu uma intervenção mediante módulo didático com alunos do $9^{\circ}$ ano do Ensino Fundamental de uma escola da rede pública da cidade de Cascavel-PR. Os dados foram coletados por meio de instrumentos diversos: montagem de relações alimentares, fichas de acompanhamento, mapas conceituais, vídeo gravação e gravação em áudio. Ao analisar as concepções prévias advindas dos alunos, decorrentes da problematização inicial, percebeu-se que esses possuíam conhecimentos sobre as relações alimentares que ocorrem entre os organismos vivos, entretanto, na análise da primeira relação alimentar, evidenciou-se a predominância de uma visão linear da cadeia alimentar. No decorrer das atividades percebeu-se que as concepções dos alunos se tornaram mais complexas, estes passaram a tecer relações alimentares não apenas de forma linear, mas de modos diversos, como redes alimentares. Considera-se que a metodologia investigativa instigou os alunos a reconstruir seu conhecimento no caso do fluxo de energia.
\end{abstract}

Palavras-chave: Ensino de Biologia, Abordagem investigativa, Fluxo de energia, PIBID.

\begin{abstract}
The current ecological knowledge indicates that all living beings, direct or indirectly, depend on solar energy to survive and that the dietary relations between living beings are not linear. The goal of the present work is to diagnose the perceptions of the students about the energy flow during the development of a courseware module with an investigative approach in the context of a program of scholarships for beginner teachers subprogram. It was developed an intervention upon the courseware module with students from the ninth grade of elementary school from a public school of the city of Cascavel-PR. The data was collected through many instruments: dietary relations
\end{abstract}




\section{Ensino, Saúde e Ambiente - V9 (3), pp. 21-43, Dez. 2016}

montages, monitoring files, conceptual maps, video recording and audio recording. By analyzing the previous conceptions deriving from students, stemming from the initial problematization, it was noticed that they possessed knowledge about the dietary relations that occur between living organisms, however, in the analysis of the first dietary relation, the predomination of a linear vision of the food-chain became evident. In the course of the activities it was noticed that the student's conceptions became more complex, they started to make dietary relations not only in a linear manner, but in many ways, as in food webs. It is considered that the investigative methodology instigated the students to rebuild their knowledge on the subject of energy flow.

Key-words: Biology Teaching, Investigative approach, Energy flow, PIBID

\section{INTRODUÇÃO}

O ensino de ciências no nível fundamental requer alternativas para que se torne mais interessante e proveitoso para o desenvolvimento social e educacional dos alunos, visando à construção do conhecimento, durante a educação básica, com a mediação do professor para auxiliá-los nesse processo. Para atingir este objetivo, Atloga e Slongo (2012, p. 2) salientam que "a educação científica escolar precisa transgredir a mera transmissão de conhecimentos, condição historicamente vivenciada nesta área". Concorda-se com as autoras que se deve incentivar o entendimento da ciência enquanto modo de explicar e compreender o mundo, mediante atividades diversificadas que desenvolvam a construção do conhecimento, buscando conceber o aluno como sujeito ativo da aprendizagem.

Foi nessa perspectiva que se desenvolveu um módulo didático cujo tema central foi "fluxo de energia". Neste, alunos da educação básica foram convidados a resolver uma situação problema de como ocorrem relações alimentares entre determinados seres vivos. A perspectiva metodológica adotada para o desenvolvimento do módulo foi a de ensino por investigação no qual, segundo Carvalho (2013), deve-se, primeiramente, propor um problema teórico ou experimental coerente com o elemento científico central do conteúdo. Em seguida deve haver a discussão da resolução do problema e, por último, fazer a comparação com atividades do cotidiano dos alunos.

O estudo aconteceu no contexto do subprojeto "Ensino de ciências e biologia por investigação: uma relação entre teoria e prática". Este subprojeto é parte do programa PIBID (Programa Institucional de Bolsa de Iniciação à Docência) de uma universidade pública do Paraná/Brasil e conta com a colaboração de três escolas públicas da região. $\mathrm{Na}$ metodologia de ensino investigativa adotada neste trabalho, de acordo com Carvalho 


\section{Ensino, Saúde e Ambiente - V9 (3), pp. 21-43, Dez. 2016}

(2010), os alunos constroem seu conteúdo conceitual ao participar do processo e com oportunidade de aprenderem a argumentar e exercitar a razão. Os professores não fornecem respostas definitivas ou impõem seus próprios pontos de vista, transmitindo uma visão fechada de ciência.

Nesse panorama, o objetivo do presente trabalho é apresentar e discutir resultados que forneçam indicativos se a abordagem didática investigativa contribuiu para a reconstrução conceitual sobre o fluxo de energia pelos alunos da educação básica de uma das escolas envolvidas no subprojeto durante o desenvolvimento de um módulo didático.

\section{A ABORDAGEM DIDÁTICA E INVESTIGATIVA}

Pesquisas atuais indicam que as tradicionais formas de ensino com a resolução de problemas para a fixação do conhecimento têm induzido os alunos a construírem conceitos "desfigurados" de conhecimentos científicos. São memorizadas informações de forma fragmentada e descontextualizada, o que não possibilita a ressignificação das mesmas pelos estudantes (AZEVEDO, 2004). Nesse contexto muitas questões emergem no pensamento dos professores como, por exemplo, as citadas por Fuman (2009, p. 5):

Por que é importante que as crianças desenvolvam o pensamento científico desde muito cedo? Como ensinar os estudantes a pensar cientificamente? Que tipo de ensino reflete o espírito da investigação científica? Como desenvolver essa prática no trabalho cotidiano das escolas?

Como mencionado por Gil Perez et al. (1992) um dos grandes problemas encontrados na construção do conhecimento científico em sala de aula está associado ao fato de haver informações subentendidas as quais não são indagadas e nem criticadas, simplesmente aceitas sem nenhuma subjeção. Na tentativa de superar tal obstáculo epistemológico os professores poderiam utilizar como metodologia o ensino por investigação. Nesta, os alunos resolvem problemas verdadeiros, levantam hipóteses para tal resolução, testam estas hipóteses e, por fim, chegam à determinada conclusão. Com este enfoque de ensino os estudantes podem perceber que a ciência não é algo concreto e acabado como é tratado nas tradicionais aulas de ciências.

Não há uma construção do conhecimento com os atuais problemas propostos pelos professores em sala de aula, na maior parte dos casos. Os habituais problemas propostos pelos professores exigem somente memorização de como se pode resolvê-los, sem que lhes proporcionem um grande esforço para solucioná-los. Os alunos ao se depararem com problemas similares aos aplicados em sala de aula são capazes de 


\section{Ensino, Saúde e Ambiente - V9 (3), pp. 21-43, Dez. 2016}

resolvê-los, porém, ao serem confrontados com novas situações, não conseguem tomar decisões. A consequência disso é que os alunos têm dificuldades de resolver problemas em suas vidas, pois não conseguem tomar decisões a fim de enfrentá-los. É importante ressaltar que, embora vários professores afirmem que utilizam em suas classes estratégias de resolução de problemas, o que de fato fazem é simplesmente resolver exercícios de fixação do que foi abordado anteriormente em sala de aula (CLEMENT; TERRAZZAN, 2012).

No ensino por investigação, o problema real é visto como parte principal para o desenvolvimento do assunto a ser tratado. É necessário desenvolver conhecimentos aprofundados sobre o tema. Em seguida, seleciona-se um problema real que tem como objetivo despertar a motivação dos alunos, visando ao desenvolvimento de uma aprendizagem a partir da metodologia investigativa. Esse problema não pode ter uma resposta imediata, porém, deve possibilitar o trabalho com o tema em forma de questionamento e levantamento de hipóteses (CAMPOS; NIGRO, 1999). Segundo Baptista (2010), o conceito de ensino por investigação é visto de forma diferente por vários autores. No entanto, a maioria deles apresenta alguns aspectos em comum como, por exemplo, identificar um problema real, levantar as hipóteses de solução, desenvolver tais hipóteses, analisar os resultados, avaliar esses resultados e chegar a certa conclusão. Para esta autora, tal metodologia de ensino resulta em desafios aos professores, pois são eles que terão que desenvolver esta metodologia dentro de sala de aula, porém é necessário o rompimento dos hábitos tradicionais de ensino.

Tais dificuldades podem ser associadas à complexidade para que uma atividade possa ser considerada investigativa. A ação do aluno não deve se limitar apenas aos trabalhos de manipulação ou observação, ela deve também conter características de um trabalho científico: o aluno deve refletir discutir, explicar, relatar, o que dará ao seu trabalho as características de uma investigação (AZEVEDO, 2004). Umas das possibilidades de trabalhar a metodologia investigativa é a utilização de problemas de lápis e papel como proposto por Clement e Terrazan (2012, p. 101):

A dinâmica de Resolução de Problemas pode desenvolver-se tanto mediante uma Atividade Didática de Problemas de Lápis e Papel, quanto de uma atividade com uso de experimento, ou ainda, de uma atividade com uso de texto. É sempre importante que se envolva situações vivenciais e que estas sejam apresentadas o mais abertas possíveis, de modo que estimulem os alunos a levantarem as "variáveis" envolvidas, os parâmetros relevantes e as possibilidades de resolução. 
O que deve ser ressaltado é que o professor não deve esquecer-se de tudo o que sabe para iniciar com o enfoque de ensino por investigação, mais, sim, reformular as maneiras com as quais já trabalham no dia a dia, ou seja, mudar somente as estratégias. Tal prática implica em desenvolver conteúdos que são trabalhados normalmente, transformando-os em oportunidades para a construção de conceitos científicos (FURMAN, 2009).

Uma das subáreas da biologia, abordadas na educação básica, que tem grande importância e pode ser compreendida pelos alunos de forma investigativa - pois requer a observação da natureza - é a ecologia. Esta área do conhecimento trata das relações entre os organismos e deles com o ambiente no qual estão inseridos. Na ecologia buscase compreender como ocorre o funcionamento dos diversos ecossistemas. Como exemplo pode-se citar a necessidade da compreensão pelos alunos de conceitos como produtores, consumidores, decompositores, teia alimentar e fluxo de energia, para conseguirem articulá-los em diferentes ecossistemas (PERTICARRARI et al., 2010). Tal necessidade está associada ao desenvolvimento de um pensamento que inclua a concepção de meio ambiente numa perspectiva ecológica.

\section{O ENSINO DE ECOLOGIA: FLUXO DE ENERGIA}

O ensino da ecologia no Ensino Fundamental, segundo Carvalho e Macedo (2009), tem a finalidade de despertar no adolescente o princípio de que o ser humano não é um ser único no ambiente que o cerca e que necessita estabelecer relações com todos os outros componentes biótipos, conciliando elementos do seu cotidiano com informações desenvolvidas no processo do conhecer, perceber e sentir, propondo um caminhar mais responsável no planeta terra.

Nos Parâmetros Curriculares Nacionais afirma-se que:

A identificação da necessidade de os seres vivos obterem nutrientes e metabolizá-los permite o estabelecimento de relações alimentares entre os mesmos, uma forma básica de interação nos ecossistemas, solicitando do aluno a investigação das diversas formas de obtenção de alimento e energia e o reconhecimento das relações entre elas, no contexto dos diferentes ambientes em que tais relações ocorrem. As interações alimentares podem ser representadas através de uma ou várias sequências, cadeias e teias alimentares, contribuindo para a consolidação do conceito em desenvolvimento e para o início do entendimento da existência de um equilíbrio dinâmico nos ecossistemas, em que matéria e energia transitam de formas diferentes - em ciclos e fluxos respectivamente - e que tais ciclos e fluxos representam formas de interação entre a porção viva e a abiótica do sistema (BRASIL, 2000, p. 17). 


\section{Ensino, Saúde e Ambiente - V9 (3), pp. 21-43, Dez. 2016}

De acordo com Motokane e Trivelato (1999), investigações sobre os processos de ensino e aprendizagem de conceitos ecológicos são necessárias para uma ampliação das reflexões sobre o ensino de ecologia. Os autores destacam ainda a importância de conhecer os conceitos espontâneos dos alunos, para servirem como elementos de construção conceitual coerente e indicação para o professor sobre o que deve ser modificado.

Dos conteúdos abordados em ecologia, a relação alimentar, quando apresentada em uma perspectiva linear, é conceituada como uma sequência de organismos em que um serve de alimento para o outro, a partir do produtor. Uma forma de representar as teias alimentares é ligar os nomes dos organismos com setas ou colocar cada ser vivo num nível trófico. Cada nível é constituído por organismos que desempenham um papel diferente. Esse elo alimentar entre os seres vivos pode ser facilmente observável na natureza: as plantas são consumidas pelos animais herbívoros, que são consumidos pelos carnívoros. Essa sequência no qual um ser vivo serve de alimento para outro, pode ser representada em forma de modelo no que se denomina de teia alimentar. Portanto, este modelo descreve também como ocorre à transferência de matéria e de energia entre os seres vivos numa cadeia alimentar (PAZ et al., 2006).

O conceito de teia alimentar é abordado na educação infantil em uma perspectiva tradicional, fragmentada e descontextualizada. Isto dificulta a apropriação da complexidade do conteúdo em níveis posteriores de escolarização. Assim, deve-se buscar desenvolver este conteúdo específico de forma não linear e contextualizada, na perspectiva da complexidade da área ecológica (MIRANDA et al, 2010; MACIEL; TERÁN, 2011).

No conhecimento biológico, as relações alimentares são representadas principalmente de duas maneiras: a primeira - presente principalmente em livros didáticos da educação básica - representa uma simplificação do fenômeno em questão e denomina-se cadeia alimentar. Esta é definida como uma série linear de organismos pela qual flui a energia originalmente captada pelos seres autotróficos fotossintetizantes e quimiossintetizantes. Cada ligação da cadeia é representada por um organismo que se alimenta daquele que o precede e serve de alimento para o organismo que o sucede. $\mathrm{Na}$ representação de uma cadeia alimentar considera-se que cada organismo ou espécie participante alimenta-se, exclusivamente, de outro organismo. A segunda forma de representação aceita atualmente na área de ecologia é denominada de teia ou rede 


\section{Ensino, Saúde e Ambiente - V9 (3), pp. 21-43, Dez. 2016}

alimentar. Compõe-se de diversas cadeias alimentares interligadas por meio de linhas que unem os diversos componentes da comunidade entres si, evidenciando suas relações alimentares, conforme Begon, Townsend e Harper (2007).

$\mathrm{Na}$ sequência apresentamos, brevemente, o contexto e o desenvolvimento do módulo didático acerca do conceito de fluxo de energia na perspectiva do ensino por investigação. Também tratamos do acompanhamento, bem como da coleta e análise dos dados.

\section{CONTEXTO DA PESQUISA E ASPECTOS METODOLÓGICOS}

O PIBID é uma ação voltada para o aprimoramento dos acadêmicos de licenciatura com o intuito de valorizar a profissão docente a partir da formação de professores para a educação básica. O programa contempla bolsas aos participantes de projetos de iniciação à docência desenvolvidos por Instituições de Educação Superior (IES) em sociedade com escolas de educação básica da rede pública de ensino. Tem como objetivo a inclusão dos acadêmicos no cotidiano das escolas públicas desde o começo de sua formação, buscando o desenvolvimento de atividades didáticopedagógicas com a orientação de um docente da licenciatura e de um professor da escola em que o projeto é desenvolvido (BRASIL, 2013).

$\mathrm{Na}$ Unioeste, o PIBID compreende quinze cursos de licenciaturas que possuem subprojetos. Cada subprojeto possui um número diferenciado de bolsistas. Em números gerais são: 15 coordenadores de área (docentes da Unioeste), 31 professores supervisores (professores da escola básica pública) e 206 bolsistas de iniciação à docência (estudantes da licenciatura). Dentre esses quinzes subprojetos encontra-se o subprojeto do curso de ciências biológicas o qual aborda uma relação entre a teoria e a prática em sala de aula com enfoque de caráter investigativo. Este objetiva o ensinar por meio de problemas reais a fim de buscar as resposta e, com isso, conseguir que haja a construção do conhecimento (JUSTINA; RIBEIRO; CASTELA, 2014).

Foi nesse contexto que se desenvolveu o módulo didático sobre fluxo de energia, o qual foi pautado nos pressupostos do ensino por investigação. O público alvo deste estudo foram alunos do $9^{\circ}$ ano do Ensino Fundamental de um Colégio Estadual da cidade de Cascavel-Pr. Os sujeitos envolvidos no desenvolvimento do módulo didático foram 17 alunos (A1 a A17).

Salienta-se que o tratamento dos dados coletados foi de caráter quantiqualitativo. A pesquisa qualitativa envolve "a subjetividade do pesquisador, bem como 


\section{Ensino, Saúde e Ambiente - V9 (3), pp. 21-43, Dez. 2016}

daqueles que estão sendo estudados, tornam-se parte do processo de pesquisa" (FLICK, 2009, p. 25). Já a metodologia quantitativa, apresenta regras de procedimentos e representatividade estática (LIMA, 2002). Conforme Queiroz (2006) há alguns anos pensava-se que a pesquisa quantitativa e a pesquisa qualitativa eram antagônicas, contudo, hoje se sabe que a combinação desses dois métodos de pesquisa pode resultar em resultados mais consideráveis e significativos.

O módulo didático foi desenvolvido para 5 horas/aula, partindo de uma situação problematizadora, como podemos observar na Figura 1. No plano 1 do módulo didático previu-se a solicitação aos alunos que construíssem um mapa conceitual com o tema fluxo de energia para avaliarmos os conhecimentos prévios desses a respeito do assunto. Os mapas conceituais podem ser utilizados pelos professores a fim de averiguar os conhecimentos prévios dos alunos e também como forma de avaliação. Segundo Moreira (1997), a avaliação dos mapas conceituais não pode ser realizada como é feito com testes de múltipla escolha, já que a análise deste instrumento é totalmente qualitativa, no qual o docente deve preocupar-se em compreender as informações ali explicitadas pelos alunos buscando evidenciar que ocorreu a construção do conhecimento. Também foi proposta a situação problema: "Monte a sequência correta de relações alimentares das figuras”, conforme a Figura 2. Essa situação problema foi elaborada tendo em vista que a primeira etapa no desenvolvimento da aula no ensino por investigação é a proposição de uma situação problema. 
Figura 1: Organograma do módulo didático.

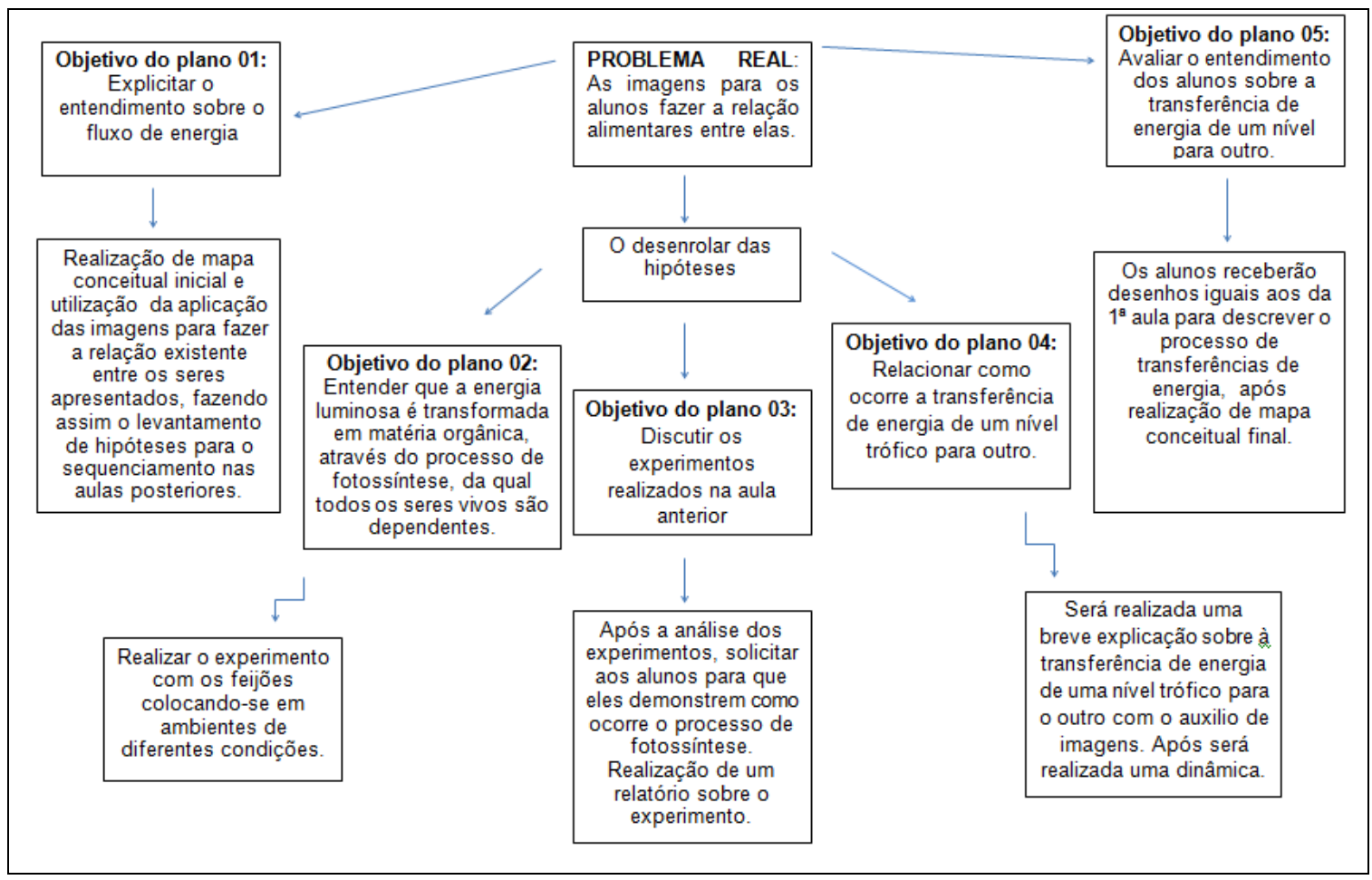

Fonte: Os Autores

Na sequência foi previsto o levantamento das hipóteses pelos alunos a partir da situação inicial, abordando o tema central "Fluxo de Energia". No plano 2 do módulo, foi proposta uma segunda questão aos alunos: "De onde vem à energia que sustenta todos os seres vivos?" Essa questão possibilitou que os alunos levantassem possíveis hipóteses. O intuito é que eles percebessem que a energia solar é a fonte primaria de energia, sem a qual não existe a manutenção da vida. Em seguida realizou-se um novo questionamento: "Como ocorre a captação da energia solar pelos seres vivos?" Ao final realizou-se um experimento prático, o qual consistia em plantar sementes de feijão em algodão e na terra para observar seu desenvolvimento. 
Figura 2: Figuras utilizadas para a montagem de relações alimentares.

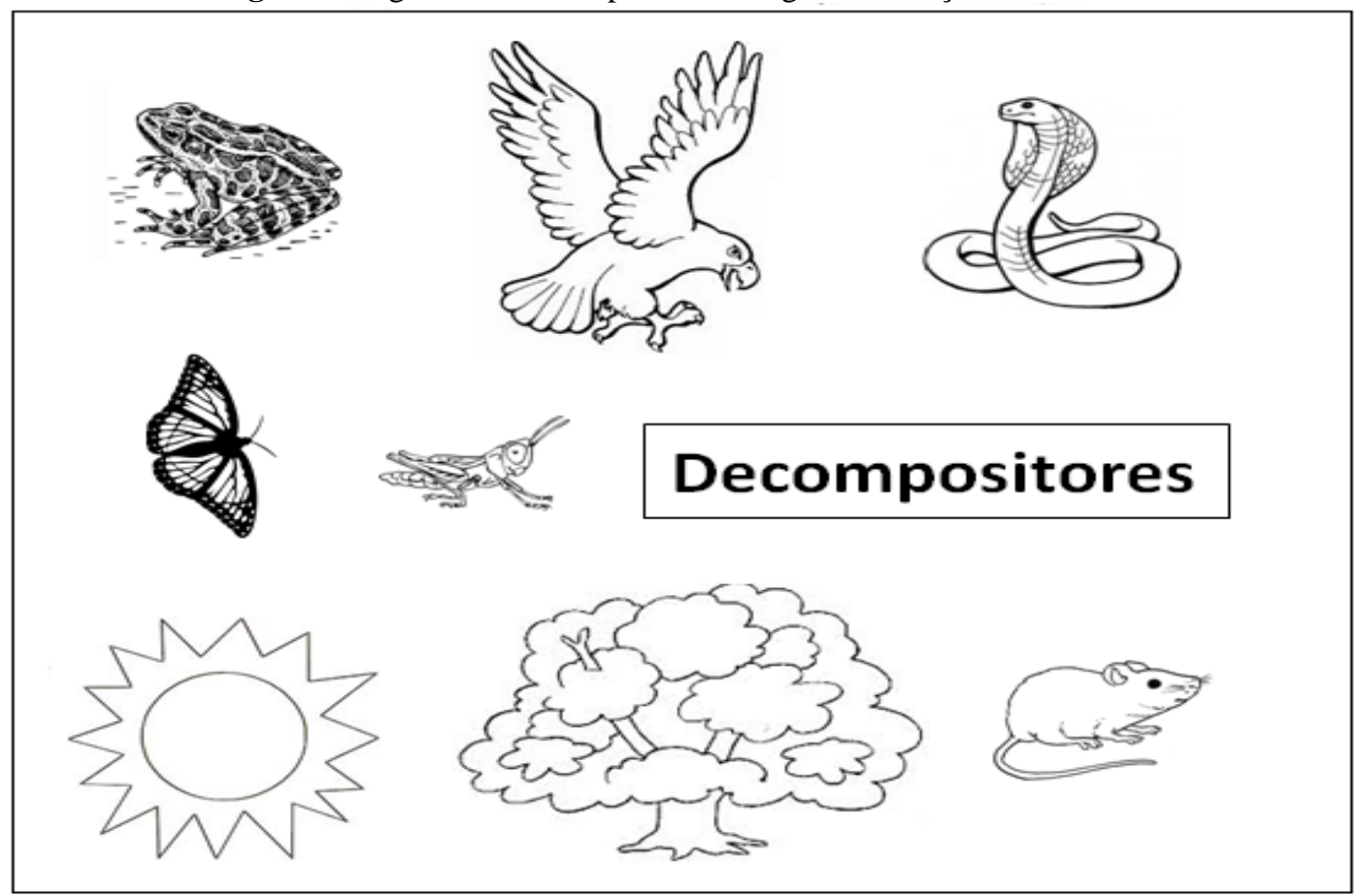

Fonte: Google Imagens

https://www.google.com.br/search?q=google+imagens\&es_sm=122\&tbm=isch\&tbo=u\&source=univ\&sa $=$ X\&ved=0CCcQsARqFQoTCJ778tCJwsgCFQaKkAodGS8JMw\&biw=1366\&bih=599

No plano 3 previu-se a observação dos experimentos realizados na aula anterior e discutir como ocorre a captação da energia luminosa pelas plantas e o que acontece com essa energia após sua captação pelos vegetais. Na sequência houve uma breve exposição acerca do processo de fotossíntese e um vídeo de Siedschlag (2013) intitulado "Fotossíntese" sobre o assunto. No plano 4, propôs-se um experimento que tinha por objetivo mostrar a passagem de energia de um organismo para outro em uma relação alimentar e observar a ação de decompositores. Neste experimento propôs-se a dinâmica na qual é passado, de mão em mão, de uns para os outros uma massa de pão grudenta que ao passar sempre ficava um pouco dessa massa nas mãos, fazendo analogia com a energia que se dissipa ao passar de um nível trófico para o outro (BERNARDO, s/d). Para finalizar, no plano 5, os alunos explicitam suas ideias sobre as relações existentes nos níveis tróficos da teia de fluxo de energia. Neste, previu-se a solicitação aos alunos para que realizassem novamente a atividade proposta na primeira aula de montagem das relações alimentares com as imagens da Figura 2, com o objetivo de reconstrução conceitual pelos alunos durante o desenvolvimento do módulo. 


\section{AVALIAÇÃO DA RECONSTRUÇÃO CONCEITUAL DOS ALUNOS}

Os resultados são apresentados e discutidos em três tópicos. Inicialmente as percepções iniciais sobre o fluxo de energia nos ecossistemas. Na sequência, as percepções durante o desenvolvimento do módulo propriamente dito. No terceiro, o enfoque centra-se nas percepções sobre o fluxo de energia ao final do desenvolvimento do módulo didático.

\section{PERCEPÇÕES INICIAIS SOBRE FLUXO DE ENERGIA NOS ECOSSISTEMAS}

Os conceitos prévios dos alunos auxiliam o professor a planejar-se para conduzir as aulas de maneira a auxiliá-los em suas dificuldades de aprendizagem (GIORDAN; VECCHI, 1996; MOTOKANE; TRIVELATO, 1999). Neste sentido, no início da primeira aula, foi solicitado aos alunos para que construíssem mapas conceituais de forma individual, para elencar as concepções iniciais acerca de fluxo de energia.

Na figura 3 apresenta-se um exemplo de mapa conceitual (A10), em relação ao fluxo de energia. É possível visualizar que A10 possui a visão de que fluxo de energia se relaciona com os conceitos de: fotossíntese (planta, O2, respiração), predador (animal), digestão, decomposição.

Figura 3: Mapa conceitual construído por A10, contendo suas concepções prévias sobre fluxo de energia.

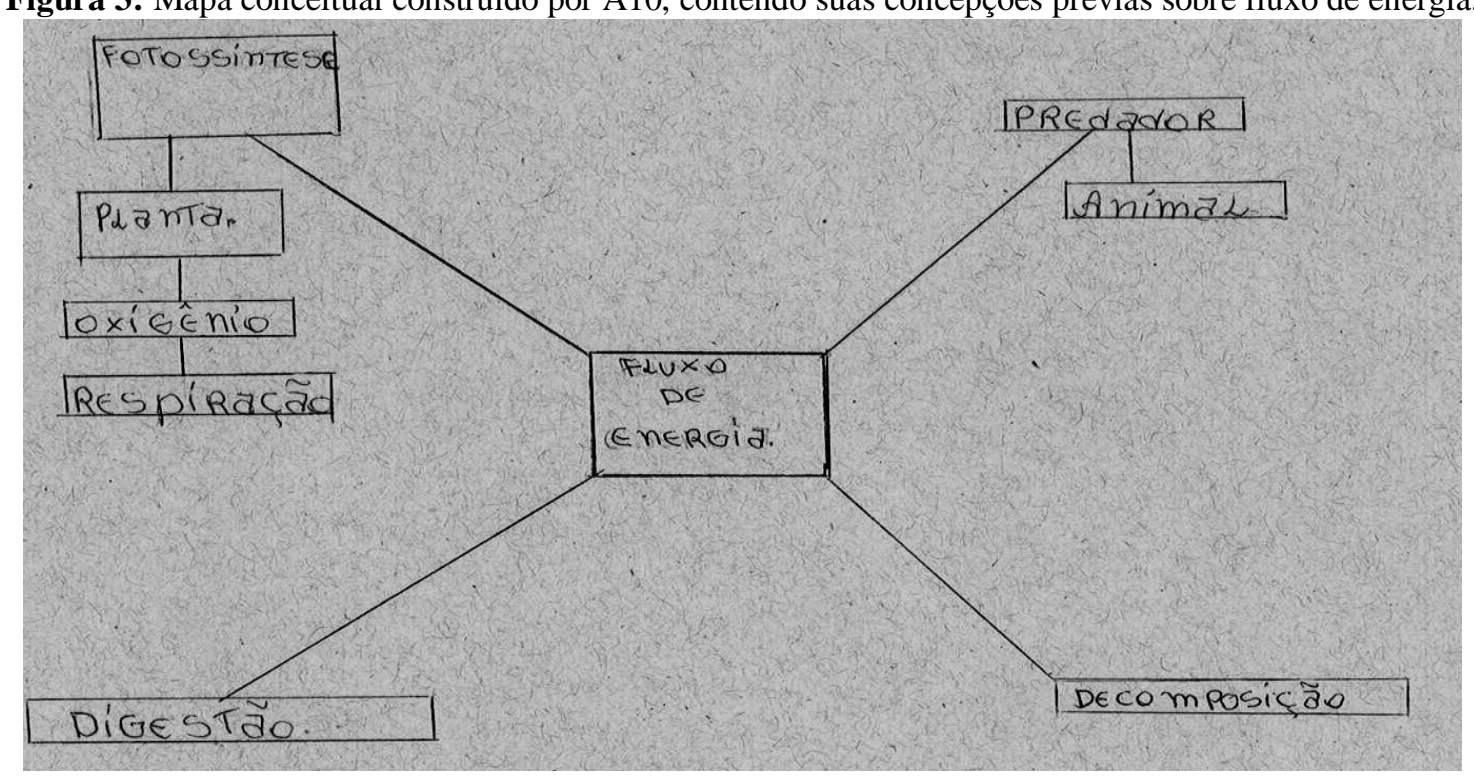

Fonte: Mapas construido pelos alunos

A partir da análise dos mapas conceituais dos sujeitos investigados pode-se evidenciar que estes possuíam conhecimentos prévios sobre o tema, no entanto, não explicitaram a relação existente entre os seres vivos e os decompositores. Também não relacionaram a digestão aos predadores e não existe um herbívoro que se alimenta de 


\section{Ensino, Saúde e Ambiente - V9 (3), pp. 21-43, Dez. 2016}

plantas e que serão predados por outros animais. Entretanto, fica evidente que os alunos tinham clareza de que são as plantas que fazem a fotossíntese que libera oxigênio para a atmosfera. De acordo com Bortoletto (2009) as informações advindas e explicitadas pelos alunos precisam ser valorizas para que esses se interessem pelo que está sendo trabalhado e, assim, tragam novos questionamentos para a sala de aula.

$\mathrm{Na}$ sequência do desenvolvimento do módulo de aula investigativa, propomos uma situação problema aos alunos, na qual esses deveriam, a partir dos exemplos de organismos apresentados (árvore, sapo, borboleta, sol, decompositores, homem, águia, grilo, rato e cobra), demonstrar como ocorrem as relações alimentares entre esses organismos, mediante a emissão de hipóteses. Essa demonstração deveria ser realizada em folha de papel sem pauta onde esses deveriam colar as figuras e relacioná-las de acordo com as possibilidades alimentares que ocorrem entre eles. O modelo de teia alimentar proposto se compõe em uma oportunidade de experiência na qual a modelização surge como maneira de aprendizagem (PAZ, et al., 2006). Cabe salientar que os alunos apresentavam apenas as concepções prévias, advindas de suas experiências anteriores.

Figura 4: Relação alimentar construída por A14.

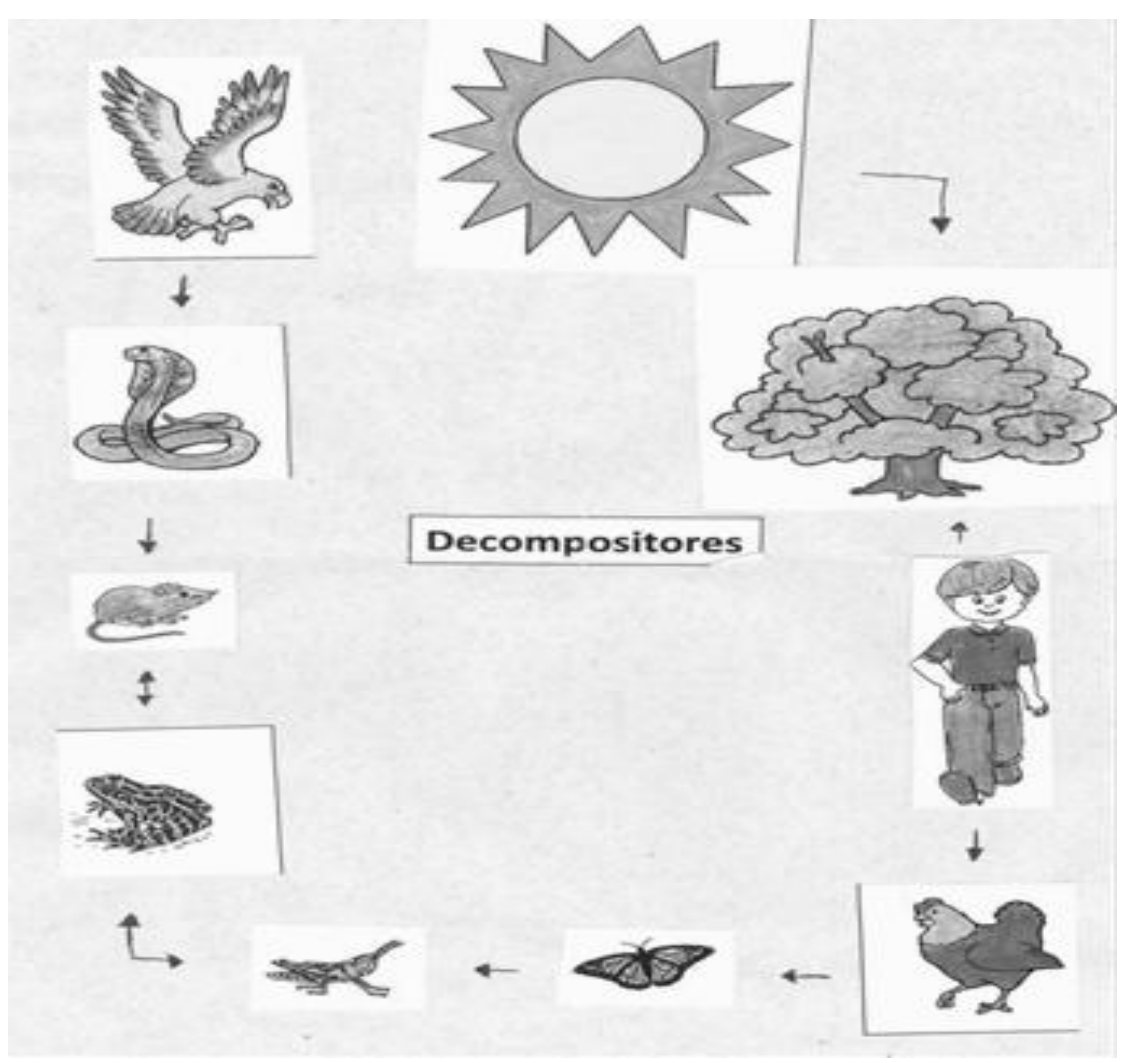

Fonte: relações estabelecidas pelos alunos 


\section{Ensino, Saúde e Ambiente - V9 (3), pp. 21-43, Dez. 2016}

Esta atividade teve como objetivo verificar o envolvimento e o emprego das informações que os alunos já apresentavam sobre o assunto, buscando o entendimento das relações alimentares entre os seres vivos. Observou-se que A14 expressa claramente a concepção de uma teia alimentar linear, não relacionando os decompositores em nenhum nível trófico.

Conforme Hasue et al. (2006), espera-se que os alunos detivessem determinados conhecimentos fundamentais como a forma de representar os níveis tróficos nas relações alimentares dos seres vivos. Entretanto para Perticarrari et al. (2010), os materiais e livros didáticos disponíveis atualmente, trazem ainda um modelo linear da teia alimentar e reforçam conceitos equívocos e mitificações sobre o assunto. Para Schneider (2012), os conceitos relativos à ecologia - tais como ecossistema, cadeia alimentar e teia alimentar - são tratados em livros didáticos de forma superficial e fragmentados. Perticarrari et al. (2010), apontam que o conteúdo do livro didático é o mais utilizado pelos professores e, desta forma, é repassado aos alunos, favorecendo somente o aprendizado dos conceitos e das terminologias e não possibilitando o envolvimento de outras metodologias.

De acordo com Borges e Rodrigues (2005), a ciência não deve ser ensinada e aprendida como fato, como um produto acabado. Ao contrário, uma das maneiras de iniciar a aprendizagem de ciência é imitando o fazer da ciência, mas com uma clara orientação de ultrapassar a mera imitação, promovendo o desenvolvimento de práticas de resolução de problemas e de avaliação da qualidade das soluções encontradas. Isso não pode ser conseguido sem o desenvolvimento concomitante de um repertório mais rico de formas discursivas e representacionais, explicativas e causais, e sem o desenvolvimento de uma atitude de busca permanente de respostas para os desafios que encontramos a todo o momento.

Desta maneira, o ensino de ecologia, mais especificamente da teia alimentar, deve ser abordado com muito cuidado pelos professores ao longo dos anos de estudo. Schneider (2012) ressalta que é preciso ensinar às crianças, desde os anos iniciais de escolarização, para que desenvolvam uma compreensão básica de alguns conceitos de ecologia. Ao introduzir, desde os anos iniciais de escolarização, conceitos temas como ecossistema, interações tróficas (cadeia e teia alimentar), fluxo de energia, o professor pode auxiliar uma aprendizagem desses conceitos em níveis escolares futuros. 


\section{Ensino, Saúde e Ambiente - V9 (3), pp. 21-43, Dez. 2016}

A tabela 1 apresenta os dados sobre as concepções prévias dos alunos a respeito das relações alimentares que ocorrem entre os seres vivos.

Tabela 1: Concepções prévias dos alunos correspondentes às relações alimentares que ocorrem entre os seres vivos

\begin{tabular}{|l|l|}
\hline Concepç̃̃es & Número de Alunos \\
\hline Cadeia alimentar & 10 \\
\hline Teia alimentar & 4 \\
\hline Não responderam & 3 \\
\hline Total & 17 \\
\hline
\end{tabular}

Fonte: Dados coletados no início da aplicação do módulo didático.

Com esses dados pode-se evidenciar que dez (A1, A4, A5, A8, A10, A11, A13, A14, A16, A17) dos discentes que participaram do módulo detinha o conceito de cadeia alimentar linear, na qual um animal se alimenta do outro sem que esteja demonstrado que as relações alimentares podem ocorrer de diversas formas e que os decompositores se encontram presentes em todos os níveis dessa teia, como os apresentados na maioria dos livros didáticos utilizado pelos professores em sala de aula. Quatro (A2, A3, A9, A15) fizeram relações condizentes com teias alimentares. Já três (A6, A12, A7) sujeitos não responderam à questão proposta.

\section{DESENVOLVIMENTO CONCEITUAL: O DESENROLAR DAS HIPÓTESES}

Com intuito de testar as diferentes hipóteses elencadas no item anterior do presente trabalho, foi proposta aos alunos a seguinte questão: "De onde vem a energia que sustenta todos os seres vivos?"

Todos os alunos responderam que a energia que sustenta os seres vivos é proveniente do sol, em seguida disseram que vem da terra, da água e dos alimentos. Então indagamos sobre como os seres vivos utilizam a energia do sol, esses responderam que as plantas realizam a fotossíntese. Quando perguntamos aos alunos como ocorre a fotossíntese e qual a sua função biológica obtivemos proposições de A3 e A9:

"a planta pega a energia do sol, pega o gás carbônico e purifica tudo e transforma em oxigênio" (A3)

"A fotossíntese pega energia solar e transforma em glicose" (A9)

$\mathrm{Na}$ aula seguinte continuamos a discussão de como ocorria o processo de fotossíntese a partir das plantas que eles visualizam no dia a dia. Após as discussões, passamos para os alunos o vídeo "Fotossíntese" (SIEDSCHLAG, 2013) no qual se 


\section{Ensino, Saúde e Ambiente - V9 (3), pp. 21-43, Dez. 2016}

explica como se dá o processo de fotossíntese, buscando a compreensão de que os seres fotossintetizantes são os responsáveis por utilizar energia solar em um processo que resulta em matéria orgânica para o seu desenvolvimento.

Em outra oportunidade - quando se buscou construir o conhecimento com os alunos de como ocorre a passagem de energia produzida através do processo de fotossíntese de um nível trófico para o outro, ou seja, das plantas para os outros seres vivos, e que nesse processo ocorre a perda de energia - propôs-se aos alunos a dinâmica da massa, conforme já descrita anteriormente no presente trabalho. No decorrer da atividade solicitamos aos alunos que papeis esses estavam desempenhando dentro da teia alimentar. Eles responderam que a aluna que pegou a massa por primeiro fazia o papel de produtor, o que a pegou depois fazia o papel dos herbívoros ou consumidores primários, o segundo fazia papel dos carnívoros ou consumidores secundários, em seguida o consumidor terciário e assim por diante. Posteriormente à atividade, os alunos lavaram as mãos e, então, indagamos qual era o papel da água no ciclo que estávamos representando e esses responderam que a água representava os decompositores.

Após a realização da atividade com a massa, questionamos se as relações alimentares seguiam esta forma linear, se todos os animais só ingeriam um mesmo tipo de alimento e esses responderam que não, pois os animais se alimentam de diferentes tipos de nutrientes, chegando à conclusão de que o fluxo de energia não ocorre de maneira linear, mais, sim, de modo complexo na forma de redes alimentares. Em seguida, solicitamos que os alunos fizessem um relatório das discussões realizadas em sala de aula e, como conclusão da aula, obteve-se respostas sobre as percepções de fluxo de energia, como nos seguintes exemplos: A5 da perda de energia de um nível para outro; e, em A8 e A12 das relações entre os organismos para a manutenção dos seres vivos.

"Conforme a energia vai passando ela vai diminuindo" (A5)

"Que a cadeia alimentar é necessária para os seres vivos" (A8)

"Eu acho que nos ensinou mais sobre como a natureza reage" (A12)

No momento seguinte apresentamos o vídeo "Cadeia Alimentar" (KLEIN, 2010), no qual se que explica como acontece o fluxo de energia nas relações alimentares que ocorrem entre os seres vivos. Juntamente com o vídeo estabeleceram-se diálogos, objetivando que os alunos chegassem à conclusão de que as relações alimentares ocorrem de maneira complexa e que não existem na natureza cadeias alimentares 
lineares, portanto, os livros que apresentam esta forma de relação alimentar somente estão exemplificando e não apresentando um modelo real de tais fenômenos biológicos.

\section{PERCEPÇÕES FINAIS}

$\mathrm{Na}$ última aula, solicitou-se aos alunos que realizassem novamente as atividades propostas no início do módulo, a fim de sintetizar o que foi estudado, conforme as figuras 5 e 6 .

Figura 5: Mapa Conceitual construído por A10 ao final do desenvolvimento do módulo didático

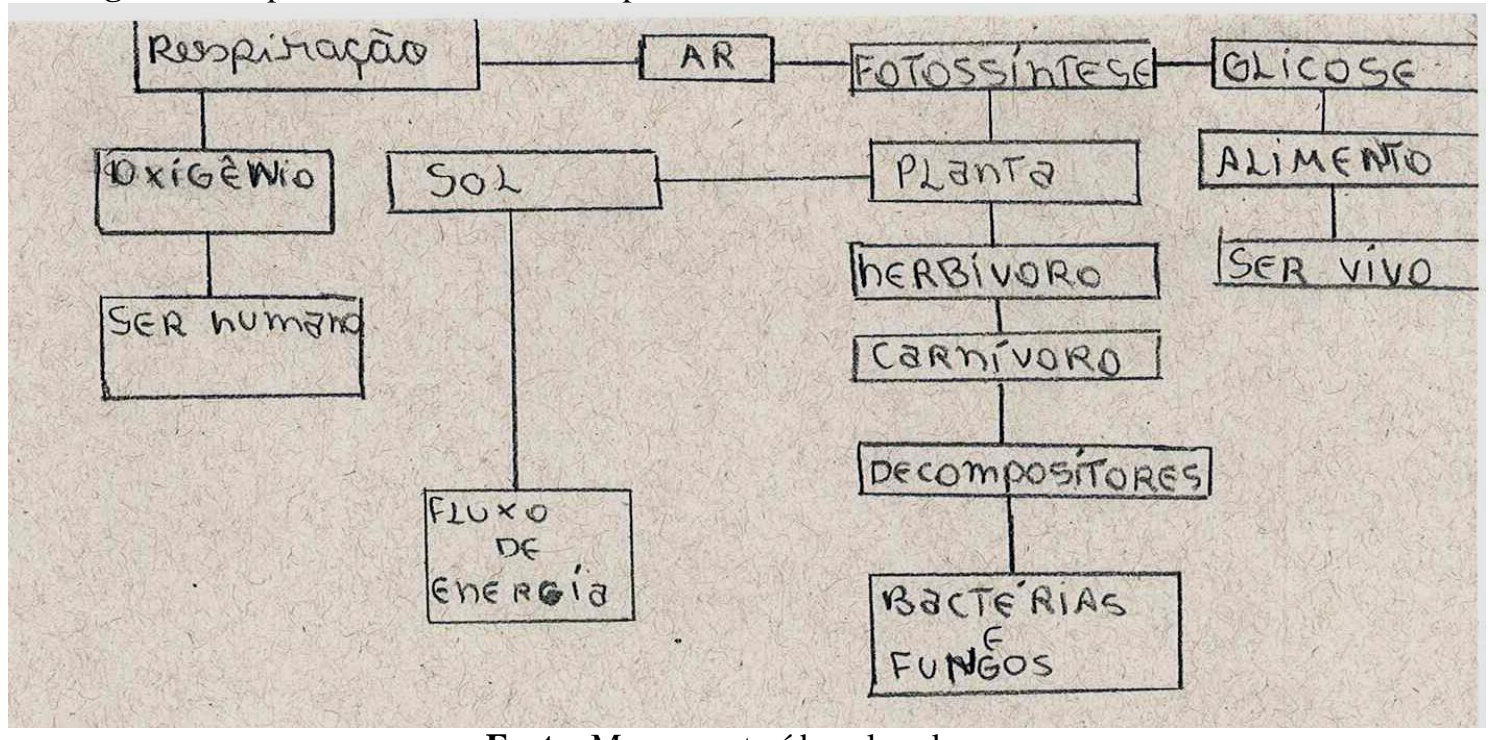

Fonte: Mapa construído pelos alunos

Ao analisar o mapa conceitual construído por A10, conforme Figura 4, ao final do módulo, comparando-o com as análises iniciais do mapa confeccionado pelo mesmo aluno (Figura 1), observou-se que houve uma ampliação dos conceitos neste mapa em relação ao primeiro, pois o aluno descreveu relações alimentares existentes entre os seres vivos que não estavam presentes no primeiro, como por exemplo: relacionou o fluxo de energia com os níveis tróficos (produtores "plantas", herbívoro, carnívoro, decompositores "fungos e bactérias"; fotossíntese, energia luminosa "sol", glicose, alimento, sobrevivência dos seres vivos "respiração, alimento, O2"). 
Figura 6: Relação alimentar construída por A14 ao final do desenvolvimento do módulo didático.

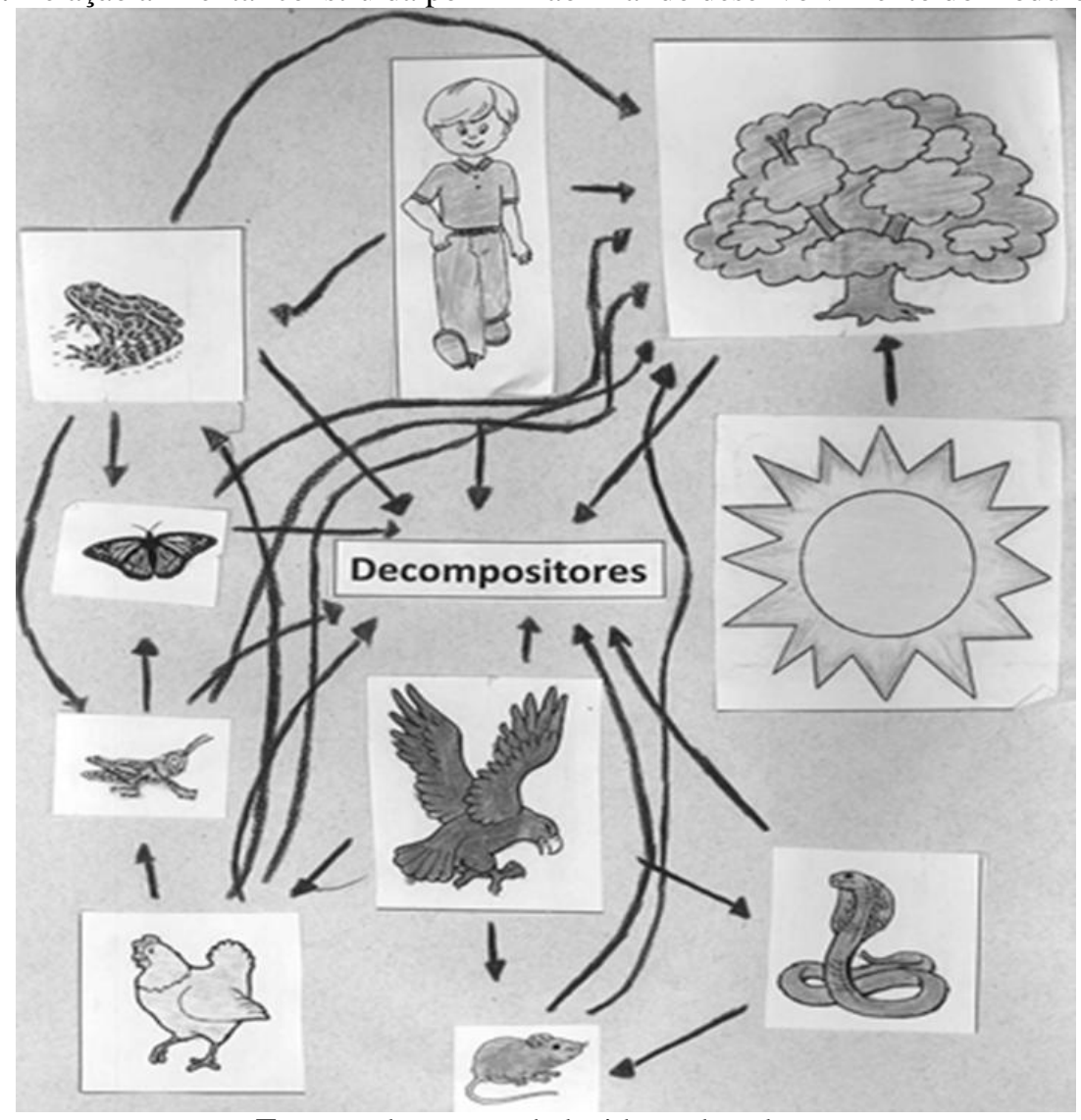

Fonte: relações estabelecidas pelos alunos

Para avaliar se os alunos haviam entendido que as relações alimentares ocorrem de forma complexa, solicitou-se que eles sintetizassem o que aprenderam com o decorrer das aulas do módulo investigativo mediante a realização da teia alimentar com os mesmos seres vivos com os quais haviam realizado essa tarefa na primeira aula, quando esses fizeram a confecção inicial das relações alimentares.

Ao analisar a segunda teia alimentar confeccionada por A14, Figura 5, verificouse uma aprendizagem significativa. Segundo Ausubel (1980), essa aprendizagem diz respeito a como uma nova informação relaciona-se com outra informação já existente, portanto, as duas informações se relacionam a fim de formar um novo conceito. Na segunda vez em que a atividade foi proposta pode-se averiguar a evolução dos conceitos apresentados pelo aluno, pois, nesta atividade, esse demonstra, claramente, a complexidade com que ocorrem as relações alimentares. Pode-se perceber o avanço dos estudantes no entendimento de como ocorrem essas relações alimentares, mostrando que o enfoque de ensino por investigação trouxe bons resultados e conseguiu promover a reconstrução do conhecimento, no caso da maioria dos sujeitos investigados, conforme Tabela 2. 
Tabela 1: Concepções apresentados pelos alunos após a aplicação do módulo didática.

\begin{tabular}{|l|l|}
\hline Concepções das relações alimentares & Número de alunos \\
\hline Cadeia Alimentar & 5 \\
\hline Teia Alimentar & 12 \\
\hline Total & 17 \\
\hline
\end{tabular}

Fonte: Dados coletados após o desenvolvimento do módulo didático.

Como demonstrado na tabela 2, houve um avanço na construção do conhecimento relacionado aos conceitos sobre as relações alimentares existentes entre os organismos. Isto fica evidente no número de alunos que deixa de ver as relações alimentares em forma de cadeia alimentar, ou seja, com uma configuração linear já que doze alunos (A1, A2, A4, A5, A6, A8, A9, A10, A11, A14, A16, A17) mostraram entender essas relações como redes alimentares e não como cadeias e cinco (A3, A7, A12, A13, A15) dos dezessete participantes demonstraram compreender essas relações de forma linear mesmo após as aulas do módulo. Desse modo, pode-se mencionar que mesmo o ensino por investigação mostrando-se uma metodologia eficiente para a maioria dos alunos, não possui um sucesso total como metodologia de ensino.

Segundo Bianchini e Zuliani (2010), o emprego deste enfoque vem sendo bastante utilizado para o avanço do processo de ensino e aprendizagem devido ao fato de o ser humano buscar a assimilação somente daquilo que instiga a sua curiosidade. Com isso, esta abordagem metodológica é capaz de despertar o encanto pela busca do conhecimento nos alunos.

De acordo com Werneck (2006), existem duas concepções de construção do conhecimento relacionada à observação dos fenômenos naturais e a construção do conhecimento a partir destas análises e outra relacionada à assimilação de conhecimentos já formados por outras pessoas. No entanto, a construção do conhecimento a que este trabalho se refere é a de aprendizagem de conhecimentos estabelecidos. Foi buscando construir conceitos já estabelecidos que utilizamos o enfoque do ensino por investigação o qual, ao se analisar os dados obtidos, mostrou-se eficiente nesta construção.

Portanto a relação de ensino e aprendizagem que ocorre na interação professoraluno traz o professor como mediador no processo de construção do conhecimento científico (FURMAN, 2009). Neste contexto é que propomos o enfoque investigativo como uma maneira de construir conceitos científicos, muitas vezes, não reconstruídos pelos alunos quando trabalhados de maneira tradicional. 


\section{TECENDO ALGUMAS REFLEXÕES SOBRE O DESENVOLVIMENTO DA ATIVIDADE INVESTIGATIVA}

No decorrer das aulas, observou-se que os alunos demonstraram certo receio com a metodologia investigativa, devido a maiorias das aulas serem ministradas mediante método tradicional de ensino, conforme demonstra a fala de A18: "Professora! Para de fazer perguntas e diz logo o que, que é a resposta”. Entretanto, foi satisfatória a participação dos mesmos durante as aulas e na realização dos trabalhos e experimentos. Contudo, os alunos mostram um desejo de obter as respostas imediatas e não buscam refletir sobre o problema. Observou-se que o envolvimento de atividades práticas investigativas (prática da fotossíntese e prática dos níveis tróficos) e atividades de lápis e papel (teia alimentar), também contribuíram para a reconstrução do conhecimento pelos alunos.

Ao analisar as concepções prévias advindas dos alunos percebeu-se que esses possuíam conhecimentos sobre as relações alimentares que ocorrem entre os organismos vivos, porém, na primeira teia alimentar proposta pelo aluno 2 , constatou-se que este tinha uma visão de que as relações alimentares se davam de maneira linear. Diante disso, em um segundo momento, foram desenvolvidas atividades a fim de desenvolver a percepção de que as relações alimentares ocorrem de maneira complexa. No decorrer destas atividades pode-se perceber as respostas dos alunos a problemas propostos e com as respostas mais problemas eram levantados e discutidos em sala de aula, buscando a interação dos conceitos científicos com os conhecimentos prévios dos alunos.

Ao final do módulo foi proposto aos alunos que realizassem novamente as atividades da primeira aula, porém que utilizassem as informações discutidas em sala. Ao comparar essas atividades pode-se evidenciar que houve a reconstrução do conhecimento por parte dos alunos, pois estes passaram a ter a visão de que as relações alimentares não se dão de forma linear, mas que essas relações ocorrem de maneira mais complexa em forma de rede ou cadeias alimentares.

\section{REFERÊNCIAS BIBLIOGRÁFICAS}

ANTLOGA. D. C.; SLONGO. I. I. P. Ensino de ciências e literatura infantil: uma articulação possível e necessária. In: ANPED SUL - SEMINÁRIO DE PESQUISA EM EDUCAÇC̃̃̃ DA REGIÃO SUL, 9., 2012. Chapecó. Anais... Chapecó, Unochapecó, 2012. p. 1-18. Disponível em:

http://www.ucs.br/etc/conferencias/index.php/anpedsul/9anpedsul/paper/viewFile/2943/ 263. Acesso em: 14/04/14 
AUSUBEL, D. P.; NOVAK, J. D.; HANESIAN, H. Psicologia educacional. Rio Janeiro: Interamericana, 1980.

AZEVEDO, M. C. P. S. Ensino por investigação: Problematizando as atividades em sala de aula. In: CARVALHO, A. M. P. C. (Org.). Ensino de Ciências: unindo a pesquisa à prática. São Paulo: Thomson, 2004. p. 19-33.

BAPTISTA, M. L. M. Concepção e implementação de actividades de investigação: um estudo com professores de física e química do ensino básico. Lisboa, 2010. Tese (Doutorado em Educação) - Instituto de Educação - Repositório da Universidade de Lisboa.

BEGON, M., TOWNSEND, C. R., HARPER, J. L. Ecologia: de indivíduos a ecossistemas. Porto Alegre: Artmed, 2007.

BERNARDO, A. R. Aula3. Ecologia, cadeias e redes alimentares, fluxo de energia. s/d. Disponível em: http://www.ufscar.br/ouroboros/aula3bio.pdf. Acesso em: 14/04/14.

BIANCHINI, T. B. ZULIANI, S. R. Q. A. Utilizando a metodologia investigativa para diminuir as distâncias entre os alunos e a eletroquímica. In: ENCONTRO NACIONAL DE ENSINO DE QUÍMICA, 15., 2010, Brasília. Anais... Brasília, UNB, 2010. P. 1-12. Disponível em: http://www.xveneq2010.unb.br/resumos/R0374-1.pdf. Acesso em: 14/04/14.

BORGES, A. T.; RODRIGUES, B. A. O ensino da física do som baseado em investigações. Ensaio - Pesquisa em Educação em Ciências. Belo Horizonte, v. 27, n.2, p. 1-23, dezembro. 2005.

BOTOLETTO, L. As monitorias interativas e valorização dos conhecimentos prévios dos alunos para a aprendizagem de conhecimentos científicos em museus e centros de ciências. In: ANAIS DO ENCONTRO NACIONAL DE PESQUISA EM EDUCAÇÃO EM CIÊNCIA, 7. 2009, Florianópolis. Anais... Florianópolis, ABRAPEC, 2009. p. 112. Disponível em: http://posgrad.fae.ufmg.br/posgrad/viienpec/pdfs/1443.pdf. Acesso em: $14 / 04 / 14$

BRASIL. CAPES. Portaria no 096, de 18 de julho de 2013, Brasília, DF, 2013. Disponível em:

<http://www.capes.gov.br/images/stories/download/legislacao/Portaria_096_18jul13_A provaRegulamentoPIBID.pdf>. Acesso em: 05/09/13.

BRASIL. Secretaria de Educação Média e Tecnológica. Parâmetros Curriculares Nacionais (Ensino Médio): Parte III - Ciências da natureza, matemática e suas tecnologias. - Brasília: MEC, 2000. Disponível em:

http://portal.mec.gov.br/seb/arquivos/pdf/ciencian.pdf. Acesso em: 17/09/13.

CADEIA alimentar. Produção de Larissa Klein. 2010. 1 vídeo de 3 min. 58 seg. Disponível em: http://www.youtube.com/watch?v=rlw1_Nx6u7s. Acesso em: 14/04/14. 
CAMPOS, M. C. C.; NIGRO, R. G. Didática de ciências: o ensino aprendizagem como investigação. São Paulo: FTD, 1999.

CARVALHO, J. M. K. MACEDO, M. Brincadeiras e ensino de ecologia: subsídios para uma educação ambiental lúdica. In: SEMINÁRIO DE EDUCAÇÃ̃O, 17., 2009, Cuiabá. Anais... Cuiabá, UFMT, 2009, p. 1-10. Disponível em: http://www.ie.ufmt.br/semiedu2009/gts/gt3/ComunicacaoOral/JUAN\%20AMARO\%20 KERSUL\%20DE\%20CARVALHO.pdf. Acesso em: 14/04/14.

CARVALHO, A. M. P. Ensino de ciências: unindo a pesquisa e a prática. São Paulo: Cengage Learning Editores, 2010.

CARVALHO, A. M. P. Ensino de ciências por investigação. São Paulo: Cengage Learning Editores, 2013.

CLEMENT, L.; TERRAZZAN, E. A. Resolução de problemas de lápis e papel numa abordagem investigativa. Experiências em Ensino de Ciências, v.7, n. 2, p.98-116, agosto, 2012. Disponível em:

http://if.ufmt.br/eenci/artigos/Artigo_ID185/v7_n2_a2012.pdf. Acesso em: 14/04/14.

FLICK, U. Introdução à pesquisa qualitativa. 3.ed. Porto Alegre: Artmed, 2009. FOTOSSÍNTESE. Produção de Camill Siedschlag. 2013. 1 vídeo de 2 min. $23 \mathrm{seg}$. Disponível em: http://www.youtube.com/watch?v=oLjjv5w3Amw. Acesso em: 14/04/14.

FURMAN, M. O ensino de ciências no ensino fundamental: colocando as pedras funcionais do pensamento cientifico. Curitiba: Sangari Brasil, 2009. Disponível em: http://www.nre.seed.pr.gov.br/goioere/arquivos/File/CIENCIAS/melina_furman.pdf Acesso em: 11/09/2013.

GIL PÉREZ, D.; TORREGROSA, M. J.; RAMIREZ, L.; CARRÉE, D. A.; GOFARD, M.; CARVALHO, A. M. P. Questionando a didática de resolução de problemas: elaboração de um modelo alternativo . Caderno Catarinense de Ensino Física, Florianópolis, v.9, n.1, p.7-19, abr.1992. Disponível em:

http://www.if.ufrj.br/ marta/aprendizagememfisica/cadbrasensfis-v9-n1-a1.pdf. Acesso em: 14/04/14.

GIORDAN, A.; VECHI, G. As origens do saber: das concepções dos aprendentes aos conceitos científicos. Porto Alegre: Artes Médicas, 1996.

HASUE, F. M.; UIEDA, V. S.; CAMPOS, L.M.L. Teia alimentar e sua aplicação em Ciências Naturais no ensino fundamental: um estudo de caso em riacho no Estado de São Paulo. In: PINHO, S. Z.; SAGLIETTI, J. R. C. (Org.). Núcleo de Ensino da UNESP. São Paulo: UNESP, 2006. p. 1-968.

JUSTINA, L.A.D.; RIBEIRO, D.M.; CASTELA, G.S. Introdução - o PIBID no estado do Paraná. In: RIBEIRO, D. M; CASTELA, G. S.; JUSTINA, L. A. D (Orgs.). 
Formação de professores no Paraná: o PIBID em foco. Porto Alegre: Evangraf, 2014. p.13-20.

LIMA M. C. Monografia: a engenharia da produção acadêmica. São Paulo: Saraiva, 2002.

MACIEL, H. M.; TERÁN, A. F. Possibilidades de alfabetização ecológica usando o tema cadeia alimentar no $6^{\circ}$ ano do ensino fundamental. In: SIMPÓSIO

INTERNACIONAL DE EDUCAÇÃO EM CIÊNCIAS NA AMAZÔNIA, 1., 2011. Disponível em:

file:///D:/Users/aline.silva9/Downloads/2011_Possibilidades\%20de\%20alfabetiza\%C3 $\% \mathrm{~A} 7 \% \mathrm{C} 3 \% \mathrm{~A} 3 \mathrm{o} \% 20 \mathrm{ecol} \% \mathrm{C} 3 \% \mathrm{~B} 3$ gica\%20usando $\% 20 \mathrm{o} \% 20$ tema\%20cadeia $\% 20$ alime ntar.pdf . Acesso em: 14/04/14.

MIRANDA, A. C. B.; JÓFILI Z. M. S.; LEÃO, A. M. A.; LINS, M. Alfabetização ecológica e formação de conceitos na educação infantil por meio de atividades lúdicas. Investigações em Ensino de Ciências, v. 15, n. 1, 2010. p. 181-200. Disponível em: http://www.if.ufrgs.br/ienci/artigos/Artigo_ID233/v15_n1_a2010.pdf. Acesso em: $14 / 04 / 2014$.

MOREIRA, M. A. Mapas conceituais e aprendizagem significativa. Porto Alegre, 1997. Disponível em: http://www.if.ufrgs.br/ moreira/mapasport.pdf. Acesso em: 14/04/14.

MOTOKANE, M.T.; TRIVELATO, S. L. F. Reflexões sobre o ensino de ecologia no ensino médio. In: ENCONTRO NACIONAL DE PESQUISA EM EDUCAÇÃO EM CIÊNCIAS. 2. 1999, São Paulo. Anais... São Paulo, USP, 1999. P. 1-11. Disponível em: http://fep.if.usp.br/ profis/arquivos/iienpec/Dados/trabalhos/G32.pdf. Acesso em 17/09/2013.

PAZ, A. M.; ABEGG, I.; FILHO, J. P. A.; OLIVEIRA, V. L. B. Modelos e modelizações no ensino: um estudo da cadeia alimentar. Ensaio - Pesquisa em Educação em Ciências. v. 8, n. 2, dezembro. 2006. p. 113 - 143. Disponível em: http://www.portal.fae.ufmg.br/seer/index.php/ensaio/article/view/113. Acesso em: $14 / 04 / 14$.

PERTICARRARI, A.; TRIGO, F. R.; BARBIERI, M. R.; COVAS, D. T. O uso de textos de divulgação científica para o ensino de conceitos sobre ecologia a estudantes da educação básica. Ciência e Educação. Bauru, v. 16, n. 2, p. 369-386, mai. 2010. Disponível em: http://www.scielo.br/scielo.php?script=sci_arttext\&pid=S151673132010000200007. Acesso em: 14/04/14.

QUEIROZ, L. R. S. Pesquisa quantitativa e pesquisa qualitativa: perspectivas para o campo da etnomusicologia. Claves, n.2, p.87-98, nov., 2006.

SCHNEIDER, M. C. A alfabetização ecológica a partir de uma horta: aproximando teoria e prática no ensino fundamental. Campo Grande, 2012. Dissertação (Mestrado em Ensino de Ciências) - Fundação Universidade Federal de Mato Grosso do Sul. 
Ensino, Saúde e Ambiente - V9 (3), pp. 21-43, Dez. 2016

WERNECK , V. R. Sobre o processo de construção do conhecimento: O papel do ensino e da pesquisa, Ensaio - Pesquisa em Ensino de Ciências, Rio de Janeiro, v.14, n.51, p. 173-196, abr./jun. 2006. Disponível em:

http://www.scielo.br/pdf/ensaio/v14n51/a03v1451.pdf. Acesso em: 14/04/14. 